\title{
Apoptosis in Response to Anti-estrogens in MCF-7 Human Mammary Adenocarcinoma Cells
}

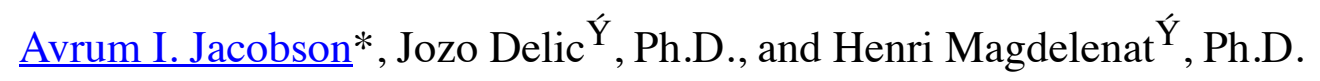

* To whom correspondence should be addressed: Faculty of Medicine, McGill University, Montreal, QC, Canada H3G 1 Y6

Ý Laboratoire de Radiopathologie, Institut Curie, F-75231 Paris 05, France

\begin{abstract}
Programmed Cell Death (PCD) is a highly regulated but not yet fully understood process by which selective gene expression leads to cell demise. The term apoptosis refers to the typical morphological changes observed with PCD. In the present study, we investigated the potential role of apoptosis as a mechanism by which anti-estrogens mediate tumor regression. Estrogen receptor-positive MCF-7 human mammary adenocarcinoma cells were treated with three different estrogen antagonists: RU 58668, ICI 182,780, and 4OH-Tam, in order of increasing potency. At selected time intervals, for up to seven days of culture, the degree of apoptosis induced by the anti-estrogens was assessed. Apoptotic cells were scored on the basis of specific morphological criteria disernable by fluorescence microscopy. It was hypothesised that the more potent the anti-estrogen, the greater the number of apoptotic cells we would observe. However, only minimal apoptosis was noted even at the highest concentration of antiestrogen assayed $\left(10^{-5} \mathrm{M}\right)$. This is in contrast to some, but not all, previous reports. Possible confounding factors are discussed and include the presence of exogenous estrogen in the culture media, as well as a genetic drift in the clonal lineage of MCF-7 cells such that a resistance to induced apoptosis had been acquired.
\end{abstract}

\section{INTRODUCTION}

Programmed Cell Death (PCD) is a highly regulated but not yet fully understood process by which selective gene expression leads to cell demise. Originally, PCD referred only to death occurring during development; however, this term is now used to designate any genetically mediated, or "programmed," death (1). The term apoptosis is derived from the Greek language and loosely translates as "the falling of leaves from trees" (2). The term refers to the typical morphological changes that one observes with PCD; however, these two terms are used interchangeably in the current literature.

PCD is the means of cell death in a wide variety of physiologic functions. These include remodelling in embryonic and post-embryonic development, normal tissue turnover, deletion of $\mathrm{B}$ and $\mathrm{T}$ cell lineages during negative selection, regression of endocrine-induced growth after the stimulus has ceased (e.g., reversion of 
lactating breast), and antibody dependent cell-mediated cytotoxicity $(2,3)$. Apoptosis is seen in all untreated tumor cells and is inducible by a wide variety of stimuli, including radiation, chemotherapy, heating, and hormone ablation (3).

Although the mechanism through which PCD acts seems to vary depending on both tissue and provoking stimulus, the morphological pattern observed follows a classic pattern, which characteristically involves scattered single cells. Histologically, there is evidence of a loss of cell-to-cell interaction as desmosomal contacts are broken down and the cell is released from the basement membrane. The cell condenses, the cytoskeleton is reorganized, and the plasma membrane becomes ruffled, forming blebs (4). At the same time, the nucleus shrinks and condenses, and the chromatin disperses into patches which tightly adhere to the nuclear envelope, forming a crescent-like pattern (5). The cell finally fragments into small membrane-bound condensed cytoplasmic fragments, called apoptotic bodies. Some apoptotic bodies contain DNA while others do not. These fragments are quickly recognized by neighboring cells and are phagocytosed (6).

It is still not clearly understood how apoptotic cells die, since all the organelles remain intact, except the endoplasmic reticulum (which dilates and fuses with the plasma membrane) and the nucleus (which fragments in a typical manner) (7). The DNA is cleaved by an intracellular endonuclease at linker regions between nucleosomes, leading to segments which are multiples of 180-200 base pairs (8). However, the DNA fragmentation is unlikely to be the cause of death. There are many cells which survive despite the lack of a nucleus; for example, both erythrocytes and lens cells are functionally enucleated. Also, $b c l-2$, a gene which protects cells from apoptosis, can prevent death even if the cell has progressed to enucleation (9). Perhaps the reason that the DNA is degraded is not to mediate death, but rather to protect the neighboring cells from engulfing potentially active genetic material (3).

Another issue which has not yet been fully explored is how the apoptotic bodies, which are encased in an intact membrane, are recognized for phagocytosis. The rapid phagocytosis which occurs suggests a highly specific mechanism. Oligosaccharide changes on the surface of the apoptotic bodies have been explored as the site of specific recognition and it has been suggested that macrophage vitronectin receptor may mediate this process $(10,11)$. Whatever the mechanism, rapid phagocytosis is critical in preventing inflammation, which would disrupt and damage the surrounding tissue (7).

The genetic control of PCD is quite complex and by no means fully understood. The genes which are involved and their protein products seem to vary in different tissues and even in the same tissue when death is induced by different stimuli. Some genes are essential for PCD and blocking their expression blocks death. Induction of PCD through expression of these genes is called the "induction mechanism" (5). Both p53 tumor suppressor gene and $c$-myc proto-oncogene have been recognized to induce apoptosis through this mechanism (12-16). Other genes, for example the proto-oncogene bcl-2 and the nematode Caenorbabditis elegans gene ced-9, protect the cell from death, and blocking their expression provokes death (17-23). This is called the "release mechanism," since the cell must be primed for death and only needs to be released from protection (5). Still other genes are up-regulated in PCD, but blockage of their expression does not necessarily lead to an absence of death; both TRPM-2 and the polyubiquitin gene are such examples (24-26). However, Delic et al. have shown that antisense blockade of ubiquitin expression inhibits irradiation-induced apoptosis in T cells; therefore, ubiquitin may also be involved in direct induction of apoptosis (27). A better understanding of the genetic encoding may lead to breakthroughs in cancer therapy with direct enlistment of apoptosis and specific tumor cell death. One exciting finding, which has tremendous therapeutic potential, is the recognition that Apo-1/Fas encodes a cell surface antigen, which when bound with its antibody, induces apoptosis $(28,29)$. When mice carrying a human B-cell tumor expressing this antigen were treated with a single injection of anti-Apo-1 antibodies, the tumor was seen to regress in a few days (29).

One-third of all women with metastatic carcinoma of the breast show at least some regression of their tumor after anti-estrogen therapy. Tumor regression results from either a decrease in proliferation or an increase in 
cell death (30). Anti-estrogen therapy is widely believed to be cytostatic, locking the cells in G1 and effectively reducing proliferation $(31,32)$. Recently, there have been conflicting reports; some suggest that anti-estrogens exert part of their action by inducing cell death, while others deny any such relation (33).

The present study was designed to further elucidate a potential role for apoptosis in mediating anti-estrogeninduced breast carcinoma tumor regression. To do so, we treated estrogen receptor positive human mammary adenocarcinoma (MCF-7) cells with one of the following anti-estrogens: 4OH-Tam, ICI 182,780, or RU 58668. 4OH-Tam is the active metabolite of Tamoxifen, and ICI 182,780 and RU 58668 are more recently developed anti-estrogens with high specificity toward the estrogen receptor. ICI 182,780 is a more potent anti-estrogen than 4OH-Tam (34-36), while RU 58668 is even more potent than ICI 182,780 (37,38). The cells were examined under fluorescent microscopy for the morphological characteristics of apoptosis; the amount of apoptosis seen was compared to a control group which had not been treated with an anti-estrogen. We hypothesized that the stronger and more specific the anti-estrogen, the greater the number of apoptotic cells we would see.

\section{MATERIALS AND METHODS}

\section{Tissue Culture}

Estrogen receptor-positive MCF-7 cells were obtained from American Type Culture Collection ( Rockville, MD, USA, Cat-no. HTB22) (39). 4OH-Tam and ICI 182,780 were gifts from Zeneca Pharmaceuticals (UK), and RU 58668 was a gift from Roussel-Uclaf (France). MCF-7 cells were cultured as monolayers in T-75 plastic tissue culture flask. Cells were routinely maintained in Dulbecco's minimally essential media (DMEM) without phenol red, supplemented with $10 \%$ fetal calf serum, $1 \%$ L-glutamine, $3.5 \mathrm{~g} / 1$ glucose, and $1 \%$ penicillin and streptomycin, and incubated at $37{ }^{\circ} \mathrm{C}$ in humidified air with $5 \% \mathrm{CO}_{2}$. Anti-estrogens, $4 \mathrm{OH}-$ Tam, ICI 182,780, and RU 58668 were dissolved in ethanol and then stored in stock solutions of $10^{-2} \mathrm{M}$ and $10^{-5} \mathrm{M}$ at $-20^{\circ} \mathrm{C}$.

Five separate trials were conducted. In each trial, MCF-7 cells plated in $35 \mathrm{~cm}^{2}$ dishes one day prior to experimentation were incubated in $5 \mathrm{ml}$ of media containing one of the three anti-estrogens at concentrations of $10^{-10} \mathrm{M}, 10^{-9} \mathrm{M}, 10^{-8} \mathrm{M}, 10^{-7} \mathrm{M}$ and $10^{-5} \mathrm{M}$. Also, in each trial, one plate was incubated without the addition of anti-estrogens, which served as controls. In the subsequent days, the cells were examined under fluorescence microscopy for the presence of apoptosis. The media were changed every second or third day and the anti-estrogens were re-administered with every change.

In the first trial, the effects of ICI 182,780 and RU 58668 at concentrations of $10^{-8} \mathrm{M}, 10^{-9} \mathrm{M}$, and $10^{-10} \mathrm{M}$, and the effects of $4 \mathrm{OH}-\mathrm{Tam}$ at concentrations of $10-7 \mathrm{M}, 10^{-8} \mathrm{M}$, and $10^{-9} \mathrm{M}$ were investigated for the four days following the addition of anti-estrogens to the media. In the second trial, the same concentrations of anti-estrogens were used. However, the duration of this trial, as well as the third and fourth trials, was extended to seven days. The third and fourth trials investigated the effect of a higher dose of anti-estrogen; $10^{-5} \mathrm{M}$ of each was used. The third trial also included a plate that had been treated with RU 58668 at a concentration of $10^{-8} \mathrm{M}$. The fifth trial was a double trial as two plates of MCF-7 cells were treated with either ICI 182,780 or RU 58668, each at a concentration of $10^{-5} \mathrm{M}$. This trial lasted five days. Trial design is summarized in Table 1.

\section{Fluorescence Microscopy}

Cells were prepared for microscopy by the addition of $5 \mu 1$ of a $0.1 \mathrm{mg} / \mathrm{ml}$ solution of HOECHST 33342 stain to each dish. The dishes were then examined under a fluorescent light microscope for the typical nuclear 
changes seen with apoptosis. These changes include nuclear condensation, a crescent-like pattern of chromatin adherent to the nuclear envelope, and the presence of apoptotic bodies (Figs. 1-3). Seven hundred cells were examined and the percentage of cells which were apoptotic was calculated. When less than one apoptotic cell was seen per two high powered fields (there were approximately 50 cells per high powered field), apoptosis was assumed to be less than $2 \%$. Fluorescence microscopy was also used to examine for mycoplasm infection.

\section{RESULTS}

The MCF-7 cells were treated with 4OH-Tam, ICI 182,780, or with RU 58668. The cells which were treated with ICI 182,780 or with RU 58668 were, at first, treated at concentrations of $10^{-8} \mathrm{M}, 10^{-9} \mathrm{M}$, or $10^{-10} \mathrm{M}$. The effect of $4 \mathrm{OH}$-Tam was examined at concentrations of $10^{-7} \mathrm{M}, 10^{-8} \mathrm{M}$, and $10^{-9} \mathrm{M}$ ( Table 1). In the first four days following treatment, the amount of apoptosis seen was always less than $2 \%$, and this was so at all anti-estrogen concentrations tested. Although in previous studies apoptosis has been observed within four days of anti-estrogen treatment $(30,40,41)$, we postulated that apoptosis might be induced to detectable levels in our system should the anti-estrogens be given more time to exert their action. The study was therefore extended to seven days, and on the sixth and seventh day following treatment slightly more apoptosis was seen; however, apoptosis did not exceed 13\%, even at the highest concentration of the most potent drug used $\left(10^{-7} \mathrm{M}, \mathrm{RU}\right.$ 58668). The fact that this finding did not reach statistical significance contrasts markedly with the reports of Wärri et al., Bardon et al., and Kyprianou et al., where up to 60\%, 62\%, and 55.9\% apoptosis was recorded, respectively $(30,40,41)$.

The above concentrations should have sufficed, since they have all been shown to be effective at concentrations lower than those used $(34,35,38,41)$. Nonetheless, a higher dose of $10^{-5} \mathrm{M}$ was then examined. Even with this high load of anti-estrogens, the amount of apoptosis induced was still not impressive. In fact, each of the three anti-estrogens were seen, at some point, to induce even slightly less apoptosis than the controls. Also, the percentage of apoptotic cells seen at this concentration never surpassed $10 \%$.

Only a modest percentage of estrogen-responsive MCF-7 human mammary adenocarcinoma cells exhibited apoptosis when treated with $4 \mathrm{OH}$-Tam at concentrations of $10^{-5} \mathrm{M}, 10^{-7} \mathrm{M}, 10^{-8} \mathrm{M}$, or $10^{-9} \mathrm{M}$, or when treated with ICI 182,780 or RU 58668 at concentrations of $10^{-5} \mathrm{M}, 10^{-8} \mathrm{M}, 10^{-9} \mathrm{M}$, or $10^{-10} \mathrm{M}$. No significant trend was seen for the more potent anti-estrogens to induce a greater amount of apoptosis.

\section{DISCUSSION}

The ability of anti-estrogen therapy to generate apoptosis in mammary carcinoma remains somewhat of a mystery. Some studies have shown that apoptosis may play an important role in tumor regression, while other studies have been unable to record significant increases in apoptosis after anti-estrogen treatment. In this study, MCF-7 cells treated with anti-estrogens were cultured in media supplemented with fetal calf serum which is known to contain variable amounts of estrogens (42). Whether our inability to detect apoptosis in the MCF-7 cells relates to the inability of the anti-estrogens (even at concentrations as high as $10^{-5} \mathrm{M}$ ) to overcome the protective effects of exogenous estrogen, or relates to the finding that anti-estrogens do not induce apoptosis in the cells tested, demands further investigation. In studies where apoptosis was seen following estrogen deprivation or estrogen antagonist therapy, including the investigations conducted by Bardon et al. (41), Kyprianou et al. (30), and Wärri et al. (40), complete estrogen withdrawal was accomplished either by ovariectomy in vivo or by dextran-charcoal treatment in vitro. When estrogens were not removed from the culture medium or tumor-bearing animal prior to anti-estrogen treatment, as in the experiments conducted by Huovinen et al.(43), only minimal amounts of apoptosis were seen. In contrast to this, Wärri et al. observed, in the presence of $10^{-9} \mathrm{M}$ estradiol, approximately $30 \%$ apoptosis after treatment 
with the anti-estrogen Toremifene. However, this was still a large reduction from the $60 \%$ apoptosis they observed if Toremifene was administered in the absence of estrogens (40). Also, a recent study by Wilson et al. failed to induce significant apoptosis when MCF-7 cells were treated with anti-estrogen ICI 182,780 in an estrogen-depleted culture medium (33); however, these cells were grown for 48 hours in a medium which contained fetal calf serum (FCS), and therefore estrogens (42), prior to being switched to an estrogen-free medium. This may have conferred resistance to apoptosis as MCF-7 cells, when pre-treated with 17ßestradiol, have been seen to develop resistance to apoptosis $(44,45)$. It has even been proposed that the reason Osborne et al. (31) and Sutherland et al. (32) observed only a cytostatic effect, without any cytotoxicity, after estrogen withdrawal was because these studies were conducted in the presence of phenol red (30), which has been reported to have weak estrogenic properties (46).

Why would estrogens reduce the amount of apoptosis induced by anti-estrogen therapy? The obvious answer is that they simply compete for the estrogen receptors (ER). However, even when anti-estrogens have been effective in reducing proliferation, the number of apoptotic cells seen has not always been significant $(33,43,47)$. The presence of estrogen has also been shown to confer resistance to apoptosis when treated with doxorubicin (45), an agent which does not exert its action through the ER. Therefore, the mechanism must be more complex. Two recent studies have established that estrogens increase the expression of bcl-2 (44,45), which, as mentioned earlier, blocks apoptosis. This may contribute to PCD resistance, but other mechanisms are probably also at play since the increased expression of $b c l-2$ may, in fact, be ER mediated and blocked by anti-estrogen treatment $(44,45)$.

The presence of estrogen cannot be found in all studies that fail to observe apoptosis. In an experiment by Kristensen et al., ZR75-1 human breast cancer xenografts did not demonstrate significant apoptosis after complete estrogen withdrawal in ovariectomized mice (47). Another possible explanation is that some cells lines may be inherently resistant. However, in the experiment by Wärri et al., which succeeded in inducing apoptosis, ZR75-1 xenografts were also used (40). Also, the induction of apoptosis has been inconsistent in studies utilizing the MCF-7 cell line $(30,33,40,41)$. As previously suggested (33), this may be because, even within the same cell line, clonal resistance may exist. Osborne et al. studied four MCF-7 cell clones obtained from four different laboratories. They found that not only did the different clones have different biological properties, including varying amounts of estrogen receptors, but the proliferation of one cell clone was unaffected by either estrogen or anti-estrogen treatment (48).

It remains unclear why the ability of anti-estrogen therapy to cause apoptosis has been extremely variable. It also remains unclear whether anti-estrogen-dependent tumor regression is mediated by apoptosis in women treated for breast cancer. Currently, estrogen antagonists are used as an alternative to ovariectomy, and not in conjunction with ovariectomy. Therefore, patients who are being treated with estrogen antagonists are not being treated in the absence of estrogen. Does this preclude the enlistment of apoptosis, and if so, are there measures which can be instituted that might oppose this estrogen dependent protection? The study of antiestrogen induced apoptosis is young and further investigation is necessary before these, as well and many other questions, can be resolved.

\section{REFERENCES}

1. Schwartz LM, Osborne BA. Programmed cell death, apoptosis and killer genes. Immunology Today 14: 582-590; 1993.

2. Wyllie AH. Apoptosis (The 1992 Frank Rose Memorial Lecture). British Journal of Cancer 67: 205-208; 1993.

3. Kerr JFR, Winterford CM, Harmon BV. Apoptosis. Its significance in cancer and cancer therapy. Cancer 73: 2013-2026; 1994. 
4. Tenniswood MP, et al. Active cell death in hormone-dependent tissues. Cancer and Metastasis Reviews 11: 197-220; 1992.

5. Cohen JJ. Apoptosis. Immunology Today 14: 126-130; 1993.

6. Kerr JFR, Wyllie AH, Currie AH. Apoptosis, a basic biological phenomenon with wide ranging implications in tissue kinetics. British Journal of Cancer 26: 239-261; 1972.

7. Dive C, Evans CA, Whetton AD. Induction of apoptosis - new targets for cancer chemotherapy. Seminars in Cancer Biology 3: 417-426; 1992.

8. Wyllie AH. Glucocorticoid-induced thymocyte apoptosis is associated with endogenous endonuclease activation. Nature 284(5756): 555-556; 1980.

9. Jacobson MD, Burne JF, Raff MC. Programmed cell death and bcl-2 production in the absence of a nucleus. EMBO Journal 13(8): 1899-1910; 1994.

10. Savill J, Dransfield I, Hogg N, Haslett C. Vitronectin receptor-mediated phagocytosis of cells undergoing apoptosis. Nature 343(6254): 170-173; 1990.

11. Duvall E, Wyllie AH, Morris RG. Macrophage recognition of cells undergoing programmed cell death. Immunology 56(2): 351-358; 1985.

12. Lowe SW, Schmitt EM, Smith SW, Osborne BA, Jacks T. p53 is required for radiation-induced apoptosis in mouse thymocytes. Nature 362(6423): 847-849; 1993.

13. Shaw P, et al. Induction of apoptosis by wild-type p53 in a human colon tumor-derived cell line. Proceedings of the National Academy of Sciences of the United States of America 89(10): 4495-4499; 1992.

14. Wyllie $\mathrm{AH}$, et al. Rodent fibroblast tumours expressing human myc and ras genes: growth, metastasis and endogenous oncogene expression. British Journal of Cancer 56(3): 251-259; 1987.

15. Evan GI, et al. Induction of apoptosis in fibroblast by c-myc protein. Cell 69(1): 119-128; 1992.

16. Shi Y, et al. Role for c-myc in activation-induced apoptotic cell death in T cell hybridomas. Science 257(5067); 221-224; 1992.

17. Hengartner MO, Ellis RE, Horvitz HR. Caenorhabditis elegans gene ced-9 protects cells from programmed cell death. Nature 356(6369): 494-499; 1992.

18. Vaux DL, Aguila HL, Weissman IL. bcl-2 prevents death of factor-deprived cells but fails to prevent apoptosis in targets of cell mediated killing. International Immunology 4(7): 821-824; 1992.

19. Sentman CL, Shutter JR, Hockenbery D, Kanagawa O, Korsmeyer SJ. Bcl-2 inhibits multiple forms of apoptosis but not negative selection in thymocytes. Cell 67(5): 879-888; 1991.

20. Hockenbery D, Nunez G., Millliman C., Schreiber RD, Korsmeyer SJ. bcl-2 is an inner mitochondrial membrane protein that blocks programmed cell death. Nature 348(6299): 334-336; 1990.

21. Nunez G, et al. Deregulated bcl-2 gene expression selectively prolongs survival of growth factor-deprived hemopoietic cell lines. Journal of Immunology 144(9): 3602-3610; 1990. 
22. Vaux DL, Cory S, Adams JM. bcl-2 gene promotes haemopoietic cell survival and cooperates with c-myc to immortalize pre-B cells. Nature 334(6189): 440-442; 1988.

23. Tsujimoto Y. Stress-resistance conferred by high level of bcl-2 alpha protein in human B lymphoblastoid cell. Oncogene 4(11): 1331-1336; 1989.

24. Schwartz LM, Myer A, Kosz L, Engelstein M, Maier C. Activation of polyubiquitin gene expression during developmentally programmed cell death. Neuron 5(4): 411-419; 1990.

25. Kyprianou N, Isaacs JT. "Thymineless" death in androgen-independent prostatic cancer cells. Biochemical and Biophysical Research Communications 165(1): 73-81; 1989.

26. Buttyan R, et al. Induction of the TRPM-2 gene in cells undergoing programmed death. Molecular and Cellular Biology 9(8): 3473-3481; 1989.

27. Delic J, Morange M, Magdelenat H. Ubiquitin pathway involvement in human lymphocyte g-irradiaitioninduced apoptosis. Molecular and Cellular Biology 13: 4875-4883; 1993.

28. Itoh N, et al. The polypeptide encoded by the cDNA for human cell surface antigen Fas can mediate apoptosis. Cell 66(2): 233-243; 1991.

29. Trauth BC, et al. Monoclonal antibody-mediated tumor regression by induction of apoptosis. Science 245(4915): 301-305; 1989.

30. Kyprianou N, English HF, Davidson NE, Isaacs JT. Programmed cell death during regression of the MCF-7 human breast cancer following estrogen ablation. Cancer Research 51: 162-166; 1991.

31. Osborne CK, Boldt DH, Estrada P. Human breast cancer cell cycle synchronization by estrogens and antiestrogens in culture. Cancer Research 44: 1433-1439; 1984.

32. Sutherland RL, Hall RE, Taylor IW. Cell proliferation kinetics of MCF-7 human mammary carcinoma cells in culture and effects of Tamoxifen on exponentially growing and plateau-phase cells. Cancer Research 43: 3993-4006; 1983.

33. Wilson JW, Wareling AE, Morris ID, Hickman JA, Dive C. MCF-7 human mammary adenocarcinoma cell death in vitro in responce to hormone-withdrawal and DNA damage. International Journal of Cancer; 61(4): 502-508; 1995.

34. Lykkesfeldt AE, Madsen MW, Briand P. Altered expression of estrogen-regulated genes in a Tamoxifenresistant and ICI 164,384 and ICI 182,780 sensitive human breast cancer cell line, MCF-7/TamR-11. Cancer Research 54: 1587-1595; 1994.

35. Wakeling AE, Dukes M, Bowler J. A potent specific pure antiestrogen with clinical potential. Cancer Research 51: 3867-3873; 1991.

36. DeFriend DJ, et al. Investigation of a new pure antiestrogen (ICI 182,780) in women with primary breast cancer. Cancer Research 54: 408-414; 1994.

37. Van de Velde P, et al. In vivo activities of RU 58668 on Tamoxifen-sensitive and Tamoxifen-resistant human mammary tumors. Unpublished 1994.

38. Van de Velde P, et al. Profil des activités pharmacologiques d'un nouvel antiestrogene pur susceptible de 
traiter certain échappements au tamoxifène. Pathologie Biologie 42: 30; 1994.

39. Esber HJ, Payne IJ, Bogden AE. Brief communication: Variability of hormone concentration and ratios in commercial sera used for tissue culture. Journal of the National Cancer Institute 50: 559-562; 1973.

40. Soule HD, Vazquez J, Long A, Albert S, Brennan M. A human cell line from a pleural effusion derived from a breast carcinoma. Journal of the National Cancer Institute 51: 1409-1413; 1973.

41. Wärri AM, et al. Apoptosis in Toremifene induced growth inhibition of human breast cancer cells in vivo and in vitro. Journal of the National Cancer Institute 85: 1412-1418; 1993.

42. Bardon S, Vignon F, Montcourrier P, Rochefort H. Steroid receptor-mediated cytotoxicity of an antiestrogen and an antiprogestin in breast cancer cells. Cancer Research 47: 1441-1448; 1987.

43. Huovinen R, Wärri A, Collan Y. Mitotic activity, apoptosis and TRPM-2 mRNA expression in DMBAinduced rat mammary carcinoma treated with anti-estrogen Toremifene. International Journal of Cancer 55: 685-691; 1993.

44. Wang TTY, Phang JM. Effects of estrogen on apoptotic pathways in human breast cancer cell line MCF7. Cancer Research 55: 2487-2489; 1995.

45. Teixeira C, Reed JC, Pratt MAC. Estrogen promotes chemotherapeutic drug resistance by a mechanism involving bcl-2 proto-oncogene expression in human breast cancer cells. Cancer Research 55: 3902-3907; 1995.

46. Berthois Y, Katzenellenbogen JA, Katzenellenbogen BS. Phenol red in tissue culture media is a weak estrogen: implications concerning the study of estrogen-responsive cells in culture. Proceedings of the National Academy of Sciences of the United States of America 83: 2496-2500; 1986.

47. Kristensen CA, Kristjansen PEG, Brunner N, Quistorff B, Spang-Thomsen M. Growth inhibition in response to estrogen withdrawal and Tamoxifen therapy of human breast cancer xenografts evaluated by in vivo ${ }^{31} \mathrm{P}$ magnetic resonance spectroscopy, creatine kinase activity, and apoptotic index. Cancer Research 55 : 4146-4150; 1995.

48. Osborne CK, Hobbs K, Trent JM. Biological differences among MCF-7 human breast cancer cell lines from different laboratories. Breast Cancer Research and Treatment 9(2): 111-121; 1987.

\section{BIOGRAPHY}

Avrum I. Jacobson is presently a fourth-year medical student at McGill University (Montreal, Quebec). His work in apoptosis was conducted at the Laboratoire de Radiopathologie, Institut Curie (Paris, France) while in his third year of medical school. The research was funded by the Rona \& Irving Levitt Family Foundation Scholarship in Oncology. His future specialty interest is Urology.

Copyright (C) 1995 by MJM 